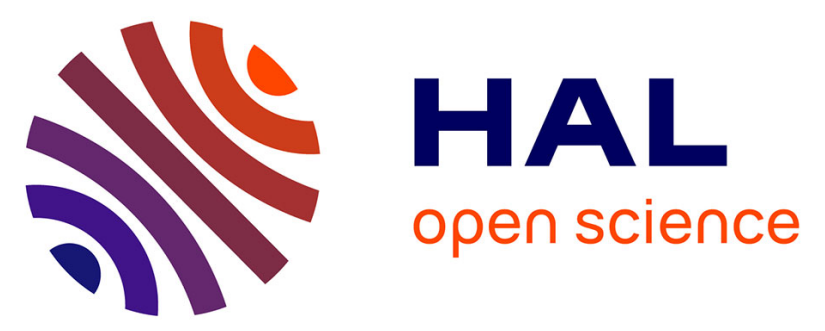

\title{
Threading dislocations in epitaxial ferroelectric PbZr0.2Ti0.8O3 films and their effect on polarization backswitching
}

Ionela Vrejoiu, Gwenael Le Rhun, Nikolai Zakharov, D Hesse, Lucian Pintilie, Marin Alexe

\section{To cite this version:}

Ionela Vrejoiu, Gwenael Le Rhun, Nikolai Zakharov, D Hesse, Lucian Pintilie, et al.. Threading dislocations in epitaxial ferroelectric PbZr0.2Ti0.8O3 films and their effect on polarization backswitching. Philosophical Magazine, 2006, 86 (28), pp.4477-4486. 10.1080/14786430600728653 . hal-00513701

\author{
HAL Id: hal-00513701 \\ https://hal.science/hal-00513701
}

Submitted on 1 Sep 2010

HAL is a multi-disciplinary open access archive for the deposit and dissemination of scientific research documents, whether they are published or not. The documents may come from teaching and research institutions in France or abroad, or from public or private research centers.
L'archive ouverte pluridisciplinaire HAL, est destinée au dépôt et à la diffusion de documents scientifiques de niveau recherche, publiés ou non, émanant des établissements d'enseignement et de recherche français ou étrangers, des laboratoires publics ou privés. 


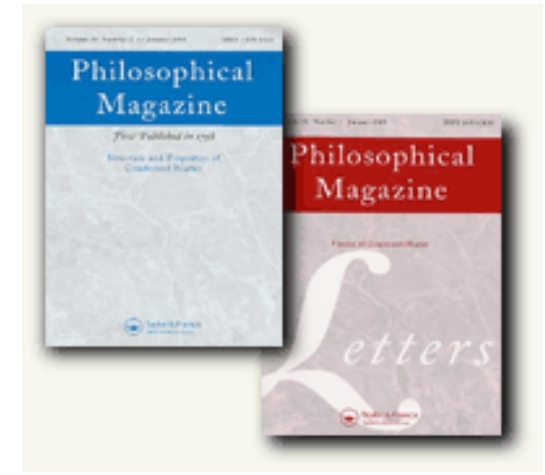

\section{Threading dislocations in epitaxial ferroelectric PbZr0.2Ti0.803 films and their effect on polarization backswitching}

\begin{tabular}{|c|c|}
\hline Journal: & Philosophical Magazine \& Philosophical Magazine Letters \\
\hline Manuscript ID: & TPHM-06-Jan-0011.R1 \\
\hline Journal Selection: & Philosophical Magazine \\
\hline $\begin{array}{r}\text { Date Submitted by the } \\
\text { Author: }\end{array}$ & 21-Mar-2006 \\
\hline Complete List of Authors: & $\begin{array}{l}\text { Vrejoiu, Ionela; Max Planck Institute of Microstructure Physics } \\
\text { Le Rhun, Gwenael; Max Planck Institute of Microstructure Physics } \\
\text { Zakharov, Nikolai; Max Planck Institute of Microstructure Physics } \\
\text { Hesse, D; Max Planck Institute of Microstructure Physics } \\
\text { Pintilie, Lucian; Max Planck Institute of Microstructure Physics } \\
\text { Alexe, Marin; Max Planck Institute of Microstructure Physics }\end{array}$ \\
\hline Keywords: & PZT, dislocations, ferroelectrics, heteroepitaxy, polarization \\
\hline Keywords (user supplied): & \\
\hline
\end{tabular}

\section{S scholaroNE" \\ Manuscript Central}




\title{
Threading dislocations in epitaxial ferroelectric $\mathrm{PbZr}_{0.2} \mathrm{Ti}_{0.8} \mathrm{O}_{3}$
}

\author{
films and their effect on polarization backswitching \\ IONELA VREJOIU*, GWENAEL LE RHUN, NIKOLAI D. ZAKHAROV, \\ DIETRICH HESSE, LUCIAN PINTILIE, MARIN ALEXE \\ Max Planck Institute of Microstructure Physics, Weinberg 2, D- 06120 Halle (Salle), \\ Germany
}

The existence of threading dislocations in ferroelectric heterostructures has been frequently reported. However, their origin and impact on the ferroelectric properties are not sufficiently understood. $\mathrm{PbZr}_{0.2} \mathrm{Ti}_{0.8} \mathrm{O}_{3} / \mathrm{SrRuO}_{3}$ heterostructures were epitaxially grown by pulsed-laser deposition (PLD) onto vicinal $\mathrm{SrTiO}_{3}(001)$ substrates. The threading dislocations exhibited by the $\mathrm{PbZr}_{0.2} \mathrm{Ti}_{0.8} \mathrm{O}_{3}$ films were investigated by cross-sectional and plan-view (high-resolution) transmission electron microscopy. Many threading dislocations were dissociated into dipoles spanning a most probably lead-rich- stacking fault. It is likely that these dislocations are able to pin $180^{\circ}$ ferroelectric domains, as suggested by a comparison between piezo-force microscope and transmission electron micrographs obtained on identical samples. Local backswitching of the polarization was observed in the vicinity of such threading dislocations.

Keywords: Heteroepitaxy; Dislocations; Ferroelectrics; PZT; Polarization 


\section{Introduction}

The heteroepitaxial growth of semiconductor materials has received a great deal of attention in the last decades. In mismatched epitaxial films, which grow in a twodimensional mode (i.e., step flow or layer-by-layer growth) biaxial stress is built up. Usually the stress relaxation in mismatched epitaxial films leads to the formation of misfit dislocations (MDs) at the film/substrate interface, which are commonly accompanied by threading dislocations (TDs) that extend across the film. Structural defects such as MDs and TDs are well known to significantly influence the physical properties of semiconductor thin films and heterostructures [1]. For example, epitaxial film quality is of great importance to the success of all III-V semiconductor devices. Dislocation densities above $\approx 10^{4} \mathrm{~cm}^{-2}$ significantly reduce the efficiency of $\mathrm{GaP}$ and GaAs optoelectronic devices. The threading dislocation density depends only marginally on the substrate material (and hence on the misfit between the substrate and the layer) but rather on the growth technique and conditions [2-5]. The possibilities for the generation of TDs during epitaxial growth are [2]:

(i) the extension of substrate dislocations,

(ii) the accommodation of translational and rotational displacements between agglomerating islands that are close to epitaxial orientation,

(iii) the formation of dislocation loops by the aggregation of point defects,

(iv) plastic deformation of the film, during growth and subsequent cooling.

Although the possible presence of TDs in (multi-)functional ternary-oxide thin films and heterostructures has been reported [6-10], details on their origin, role, and particularly avoidance, are not sufficiently understood.

Here we report our observations on heteroepitaxial structures of $\mathrm{PbZr}_{0.2} \mathrm{Ti}_{0.8} \mathrm{O}_{3} / \mathrm{SrRuO}_{3} / \mathrm{SrTiO}_{3}$ (001), whose ferroelectric $\mathrm{PbZr}_{0.2} \mathrm{Ti}_{0.8} \mathrm{O}_{3}$ film exhibits 
threading dislocations, in addition to $90^{\circ}$ and $180^{\circ}$ ferroelectric domains. $180^{\circ}$ ferroelectric domains are domains with the polar $c$-axis perpendicular to the surface plane of the heterostructure, either pointing towards the PZT/SRO interface or to the top surface. Piezo-force microscopy (PFM) investigations revealed that local backswitching of the $180^{\circ}$ ferroelectric domains occurs. These results let us assume that TDs may pin the domains and hinder the ferroelectric switching.

\section{Experimental}

Vicinal single crystalline $\mathrm{SrTiO}_{3}(100)$ (STO) substrates with a miscut angle of $0.1^{\circ}$ $0.2^{\circ}$ (CrysTec, Germany) with single-unit-cell stepped terraces were used to grow the heterostructure epitaxially $[11,12]$. The thin films were fabricated by PLD, employing a $\mathrm{KrF}$ excimer laser $(\lambda=248 \mathrm{~nm})$. Ceramic targets of $\mathrm{SrRuO}_{3}$ (purchased from PRAXAIR) (SRO) and of $\mathrm{Pb}_{1.1}\left(\mathrm{Zr}_{0.2} \mathrm{Ti}_{0.8}\right) \mathrm{O}_{3}$ (SCI Engineered Materials) (PZT) were used for in situ thin film deposition. The SRO layer was chosen as the bottomelectrode for the heterostructure. It was deposited at a substrate temperature $\mathrm{T}_{\mathrm{g}}=$ $700^{\circ} \mathrm{C}$ in a background atmosphere of 100 mTorr oxygen, with a laser fluence $\Phi_{\mathrm{L}}=$ $1.5-2 \mathrm{~J} / \mathrm{cm}^{2}$, at a laser repetition rate of $5 \mathrm{~Hz}$. The SRO grew in step-flow growth mode [8,9], exhibiting single-unit-cell stepped terraces. The subsequent PZT film (100-350 nm thick) was grown at $\mathrm{T}_{\mathrm{g}}=575-600{ }^{\circ} \mathrm{C}$ in $150-300 \mathrm{mTorr}$ oxygen, at $\Phi_{\mathrm{L}}=$ $2-3 \mathrm{~J} / \mathrm{cm}^{2}$, and at a laser repetition rate of 5 or $10 \mathrm{~Hz}$. For macroscopic ferroelectric measurements (not shown) circular SRO top-electrodes $(340 \mu \mathrm{m}$ diameter) were deposited by PLD at room temperature through a shadow-mask and then platinum was sputter-deposited on top of the SRO, in order to ease the contacting of the capacitor pads. 
Transmission electron microscopy (TEM) samples were prepared by standard mechanical and ion-beam thinning procedures [13]. TEM and high-resolution TEM (HRTEM) were performed on plan-view samples and on two types of cross-section samples, cut in such a way that the electron beam was incident onto the sample either from the [010] or the [110] direction. Some of the HRTEM images were Fourierfiltered. Conventional TEM was performed in a Philips CM20T electron microscope at $200 \mathrm{keV}$ primary energy of the electrons, and HRTEM in a Jeol 4010 high resolution electron microscope at $400 \mathrm{keV}$.

Local piezoresponse behaviour was investigated by a scanning probe microscope (ThermoMicroscope) in PFM mode. PtIr coated tips (Nanosensors, ATEC-EFM) with an elastic constant of about $2.5 \mathrm{~N} / \mathrm{m}$ were employed [14]. Local piezoelectric hysteresis curve was acquired by superimposing a d.c. bias voltage on the a.c. probing voltage $(1 \mathrm{~V}, 22.3 \mathrm{kHz})$. For quantitative measurements the piezoresponse signal was previously calibrated using a X-cut quartz crystal $\left(\mathrm{d}_{33}=2.3\right.$ $\mathrm{pm} / \mathrm{V})$.

\section{Results and discussion}

PFM investigations performed on a PZT/SRO/STO heterostructure revealed some intriguing aspects regarding the switching of $180^{\circ}$ ferroelectric domains. Figure 1a shows the surface topography of a $2 \mu \mathrm{m} \times 2 \mu \mathrm{m}$ area of the as-grown PZT film. The two-dimensional grid exhibited by the surface indicates that $90^{\circ}$ twin domains, typical for $c$-axis oriented tetragonal PZT films above a certain critical thickness $[7,15,16]$, were formed. The piezoresponse image of the as-grown PZT film, associated with the topography image is given in Fig. 1b. The piezoresponse image confirms the existence of $90^{\circ}$ domains, with the dark lines (forming a grid) representing the $a$ - 
domains (i.e., domains with the polar $c$-axis lying in the plane of the film) $[14,16]$. $180^{\circ}$ domains of "up" preferential orientation of the polarization are present in the PZT film $[7,11,14]$, their piezoresponse being displayed as bright irregular spots with various lateral sizes between about 50 and $200 \mathrm{~nm}$. In order to investigate the switching behaviour of these $180^{\circ}$ domains, the following experiment was performed. The top left quadrant $(1 \mu \mathrm{m} \times 1 \mu \mathrm{m})$ of the $2 \mu \mathrm{m} \times 2 \mu \mathrm{m}$ area was poled by $-4 \mathrm{~V}$, and the bottom right quadrant $(1 \mu \mathrm{m} \times 1 \mu \mathrm{m})$ was poled oppositely by $+4 \mathrm{~V}$. The piezoresponse image of the overall area, acquired immediately after the poling procedure is shown in Fig.1c. Complete switching to positive polarization occurred in the positively biased area, whereas in the negatively poled area, some of the positive $180^{\circ}$ domains did not completely switch to negative polarization. The sample was left on the PFM stage for 15 hours and the same $2 \mu \mathrm{m} \times 2 \mu \mathrm{m}$ area was scanned again, the resulting image being displayed in Fig. 1d. In the previously positively poled quadrant, no modification of the polarization pattern was observed. However, in the negatively poled area backswitching from the negative polarization to the positive polarization state took place, as many of the initial bright spots reappeared at the very same location.

'[Insert figure 1 about here]'

To study possible origins of this backswitching of $180^{\circ}$ ferroelectric domains in terms of pinning by structural defects, cross-section and plan-view (HR-)TEM investigations were carried out. Figure $2 \mathrm{a}$ is a cross-section TEM micrograph of a PZT/SRO/STO heterostructure, seen from [010] direction. The tetragonal film was $c$ axis oriented, as shown by the electron diffraction pattern (Fig. 2e), but contained 
narrow $90^{\circ} a$-domains bounded by $\{101\}$ twin planes $\left(90^{\circ} a\right.$-c-boundaries) (see Fig. 2a, where the tilted white arrows are inserted). Typically two types of vertical threading dislocations (TDs) were discovered in the PZT film. There exist pairs of partial dislocations (partial dislocation dipoles) that run across the entire layer [7] (indicated by the black arrows) and half-loops $[1,2]$ (indicated by the white doublearrow) that come from the top surface and end in the bulk of the PZT film. The TD dipoles that cross the whole PZT layer go through the $a$-domains as well, which indicates that the TD dipoles are already formed at the growth temperature [7]. The twin domains are known to start being formed during the cooling of the heterostructure through the cubic-to-tetragonal structural phase transition. The temperature at which the PZT layers are usually grown, $\mathrm{T}_{\mathrm{g}}$, significantly exceeds the phase transition temperature $\left(\mathrm{T}_{\mathrm{C}} \approx 450{ }^{\circ} \mathrm{C}\right)$. It can be seen that sometimes the halfloop dislocations may pin a $90^{\circ}$ domain (Fig. 2b).

'[Insert figure 2 about here]'

Plan-view TEM micrographs are shown in Fig. 2c, d. $90^{\circ}$ domains are visible in Fig. 2c, as well as black spots spread over the entire viewed area. These spots can be better seen in the higher magnified image, given in Fig. $2 \mathrm{~d}$. They turned out to be dislocation dipoles with a typical separation distance of $10-50 \mathrm{~nm}$. To further elucidate the nature of these threading dislocation dipoles, (110)-Fourier filtered planview HRTEM images were taken. Fig. 3 shows such an image. It reveals that the TD dipole consists of two partial edge dislocations of equal in-plane Burgers vector component, $\mathrm{b} \|=(\mathrm{a} / 2)[110][1,2,14](0.28 \mathrm{~nm})$, but of opposite sign, separated by a distance of $15 \mathrm{~nm}$. The vector (a/2)[110] represents half of a lattice vector, in view of 
the primitive cubic unit cell of PZT. As indicated by cross-sectional HRTEM of a single half-loop TD (Fig. 4a, b), half-loop TDs have an out-of-plane Burgers vector component $b_{\perp}=(c / 2)[001]$ and thus represent partial dislocations too. Although neither the half-loops nor the dipoles have been entirely characterized in terms of their Burgers and line vectors, we may state that partial in-plane Burgers vector components $b_{\|}=(a / 2)[110]$ and partial out-of-plane components $b_{\perp}=(c / 2)[001]$ have been detected.

'[Insert figure 3 and figure 4 about here]'

Diffraction contrast TEM and HRTEM images of the PZT/SRO/STO heterostructures showed that the partial dislocation dipoles include a stacking fault (SF) in between [2,17-19], as seen in Fig. 5a and 5b, respectively. The black arrow indicates the location of one of the numerous SFs. Figure 5c is a HRTEM image seen from the [110] direction, so that the (001) PZT planes and the SF are visible edge-on. This image was taken on a very thin sample area (weak phase object) at Scherzer defocus $(-40 \mathrm{~nm})$, which allows to assume that cations are visualized as dark spots (,,intuitively interpretable image“, $c f$. [20]). In view of these imaging conditions, the very dark elongated contrast spots, which occur along the stacking fault, can most probably be assigned to pairs of lead cations. Thus the stacking faults are most probably lead-rich. An unambiguous allocation of the elongated contrast spots to lead ions would, however, require some detailed contrast simulation work; thus the possibility of a titanium-rich stacking fault, as described in Ref. [21], cannot be entirely excluded. In any case, the stacking fault should be metal-rich in nature. In Figure 6, a schematic model is given which refers to the possibility of a lead-rich 
stacking fault. This model involves an in-plane displacement vector component $R_{\|}=$ (a/2)[110] (schematic top) and an out-of-plane displacement vector component $\mathrm{R}_{\perp}=$ (c/2)[001] and is thus in accordance with the experimental findings for the respective Burgers vector components. The changed linking of the oxygen-octahedra at the stacking fault is equivalent to an oxygen deficiency (see Fig. 6, schematic seen from [1ํㅣ direction). In our case, the dislocation loops may form by aggregation of point defects (i.e., oxygen vacancies) $[1,2]$. Because the growth of the thin film often occurs under non-equilibrium and high supersaturation conditions, as it is certainly the case for typical PLD conditions [22-24], it can be anticipated that an excess of vacancies or gas atoms could be trapped in a growing film. These point defects could aggregate to form dislocation loops that would subsequently grow and coalesce to form dislocations threading the thin film. Therefore, it is likely that non-stoichiometry of the growing film could lead to dislocations being produced by the mechanism under discussion [2]. The PZT target we employed for PLD, although of $\mathrm{Pb}_{1.1}\left(\mathrm{Zr}_{0.2} \mathrm{Ti}_{0.8}\right) \mathrm{O}_{3}$ nominal composition, may have already been oxygen-deficient, as it is suggested by its dark-gray color, and this may have contributed to the slightly non-stoichiometric deposits. The target was deliberately purchased with $10 \% \mathrm{PbO}$ excess, as a precaution for the possible loss of $\mathrm{PbO}$ during the deposition, because $\mathrm{PbO}$ is highly volatile at the usually elevated growth temperature. Moreover, the correct oxygen content of the growing film was expected to be ensured by the background oxygen atmosphere, as the depositions were performed in 150-200 $\mathrm{mTorr}_{2}$. PLD is known to be a deposition technique that, under favourable conditions, allows for stoichiometric transfer of the material from the bulk target to the growing thin film $[22,23]$. However, we would expect that small deviations from the nominal composition are likely to be exhibited by these PZT films. Electron-energy loss spectroscopy (EELS) 
'[Insert figure 5 and figure 6 about here]'

Another observation related to the formation of TDs starting from the PZT/SRO interface is that the TDs may originate on a particulate "P", as it can be seen in Fig .7. This can be a source for heterogeneous nucleation of dislocation dipoles [1]. The particle (10-15 $\mathrm{nm}$ in diameter) appears to be amorphous (better visible in the top left inset of Fig. 7) and may be either an impurity, a particulate ejected from the PLD target or may be formed on the SRO surface at the initial stage of the PZT layer growth. It is assumed that the presence of such a particle or impurity results in stress concentrations which can extend into the epilayer.

'[Insert figure 7 about here]'

Considering our up to date observation [11], according to which TD half loops, TD dipoles and backswitching $180^{\circ}$ domains are all absent in layer-by-layer grown, defect-free $\mathrm{PbZr}_{0.2} \mathrm{Ti}_{0.8} \mathrm{O}_{3}$ films deposited on $\mathrm{SrRuO}_{3} / \mathrm{SrTiO}_{3}(001)$, whereas they all show simultaneously up in the present films, it is reasonable to assume that TD half loops and/or TD dipoles (with their lead-rich stacking faults) may represent pinning centers for backswitching $180^{\circ}$ domains. As a consequence, the observed TDs are potential pinning centers for $180^{\circ}$ ferroelectric domains, inhibiting their switching when subjected to a reverse-oriented electric field. Moreover, the remnant polarization of the PZT films we report on here was around $\mathrm{P}_{\mathrm{r}}=70 \pm 10 \mu \mathrm{C} / \mathrm{cm}^{2}$, 
whereas the defect-free films have a remnant polarization [11] up to $\mathrm{P}_{\mathrm{r}}=105 \pm 5$ $\mu \mathrm{C} / \mathrm{cm}^{2}$. The defect-free PZT layers also did not exhibit backswitching of the polarization [11]. This strengthens our opinion that threading dislocations can play an important role in the polarization backswitching. The lateral spacing between $20 \mathrm{~nm}$ and about $120 \mathrm{~nm}$ of the TD dipoles and of the TD half loops at the surface of the films, and the lateral dimension of the backswitching ferroelectric $180^{\circ}$ domains, which is between $50 \mathrm{~nm}$ and about $200 \mathrm{~nm}$, are also in accordance with this assumption.

\section{Conclusions}

In conclusion, PFM investigations have established that preferentially oriented $180^{\circ}$ domains present in tetragonal PZT epitaxial films undergo backswitching after being reversed by an applied electric field. TEM and HRTEM revealed that partial threading dislocation half-loops and partial dislocation dipoles exist in these films. The latter include a - most probably lead-rich- stacking fault in between. It is suggested that these TDs act as pinning centers for the $180^{\circ}$ domains and inhibit their switching.

\section{Acknowledgements}

The work has been partly funded by Volkswagen Foundation, through the "Nanosized ferroelectric hybrids" project no I/80897 and partly by DFG through FOR 404. Sincere thanks are due to S. Swatek and N. Schammelt (MPI, Halle) for the TEM sample preparation and assistance in PLD-system maintenance, respectively.

\section{References}

[1] E. A. Fitzgerald, Mater. Sci. Rep. 787 (1991). 
[2] J. W. Matthews, Epitaxial Growth, Part B Academic Press, New York (1975).

[3] M. -C. Miguel and M. Kardar, Phys. Rev. B 5611903 (1997).

[4] V. M. Kaganer, O. Brandt, A. Trampert, and K. H. Ploog, Phys. Rev. B 72045423 (2005).

[5] D. Kapolnek, X. H. Wu, B. Heying, S. Keller, B. P. Keller, U. K. Mishra, S. P. DenBaars, and J. S. Speck, Appl. Phys. Lett. 671541 (1995).

[6] B. Heying, E. J. Tarsa, C. R. Elsass, P. Fini, S. P. DenBaars, and J. S. Speck, J. Appl. Phys. 856470 (1999).

[7] S. P. Alpay, V. Nagarajan, L. A. Bendersky, M. D. Vaudin, S. Aggarwal, R. Ramesh, and A. L. Roytburd, J. Appl. Phys. 853271 (1999).

[8] C. L. Canedy, H. Li, S. P. Alpay, L. Salamanca-Riba, A. L. Roytburd, and R. Ramesh, Appl. Phys. Lett. 771695 (2000).

[9] I. B. Misirlioglu, A. L. Vasiliev, S. P. Alpay, M. Aindow, and R. Ramesh, J. Mater. Sci. 41697 (2006).

[10] I. B. Misirlioglu, S. P. Alpay, M. Aindow, and V. Nagarajan, Appl. Phys. Lett. 88102906 (2006).

[11] I. Vrejoiu, G. Le Rhun, L. Pintilie, D. Hesse, and M. Alexe, accepted by Adv. Mater.

[12] W. Hong, H. N. Lee, M. Yoon, H. M. Christen, D. H. Lowndes, Z. Suo, and Z. Zhang, Phys. Rev. Lett. 95095501 (2005).

[13] D. B. Williams and C. B. Carter, Transmission Electron Microscopy, Plenum Press, New York (1996).

[14] G. Le Rhun, I. Vrejoiu, L. Pintilie, D. Hesse, and M. Alexe, submitted to Nanotechnology.

[15] A. L. Roitburd, Phys. Stat. Sol. (a) 37329 (1976). 
[16] S. Ganpule, V. Nagarajan, H. Li, A. S. Ogale, D. E. Steinhauer, S. Aggarwal, E. Williams, R. Ramesh, and P. De Wolf, Appl. Phys. Lett. 77292 (2000).

[17] W. Wunderlich, M. Fujimoto, and H. Ohsato, Thin Solid Films 375, 9 (2000).

[18] A. Lankinen, T. Tuomi, J. Riikonen, L. Knuuttila, H. Lipsanen, M. Sopanen, A. Danilewsky, P. J. McNally, L. O’Reilly, Y. Zhilyaev, L. Fedorov, H. Sipilä, S. Vaijärvi, R. Simon, D. Lumb, A. Owens, J. Cryst. Growth 283, 320 (2005).

[19] C. J. Lu, L. A. Bendersky, K. Chang, and I. Takeuchi, J. Appl. Phys. 93512 (2003)

[20] D. van Dyck, High-resolution electron microscopy, in: Electron Microscopy Principles and Fundamentals, edited by S. Amelinckx, D. van Dyck, J. van Landuyt, and G. van Tendeloo (VCH-Wiley, Weinheim, 1997, pp. 125 ff).

[21] C. J. Lu, L. A. Bendersky, K. Chang, and I. Takeuchi, Phil. Mag. 831565 (2003)

[22] D. Bäuerle, Laser Processing and Chemistry, $3^{\text {rd }}$ ed., (Springer, New York, 2000).

[23] R. Willmott, and J. R. Huber, Rev. Mod. Phys. 72, 315 (2000).

[24] G. Koster, Artificially layered oxides by Pulsed Laser deposition. Ph. D. thesis, University of Twente (1999). 


\section{Figure captions}

Figure 1 PFM investigations on a $\mathrm{PbZr}_{0.2} \mathrm{Ti}_{0.8} \mathrm{O}_{3} / \mathrm{SrRuO}_{3} / \mathrm{SrTiO}_{3} \quad(001)$ heterostructure: a- iamge of the PZT surface topography $(2 \mu \mathrm{m} \times 2 \mu \mathrm{m})$ and bpiezoresponse image acquired by scanning the area shown in (a); c- piezoresponse image acquired in the very same area, immediately after poling the top left corner (1 $\mu \mathrm{m} \times 1 \mu \mathrm{m})$ with $-4 \mathrm{~V}$ and the bottom right corner by $+4 \mathrm{~V}$; d- piezoresponse image of the very same area acquired by scanning 15 hours after the poling. In (c) and (d) the dashed lines were added to guide the reader's eye.

Figure 2 Cross-section (a, b, seen from [010]) and plan-view (c, d, seen from [001]) TEM micrographs of $\mathrm{PbZr}_{0.2} \mathrm{Ti}_{0.8} \mathrm{O}_{3} / \mathrm{SrRuO}_{3} / \mathrm{SrTiO}_{3}$ (001) heterostructrures. In (a) the inclined white arrows indicate the $90^{\circ}$ a-c boundaries and the white double-arrow indicates a dislocation half-loop; the black arrows point out the threading dislocation dipoles that cross the entire PZT layer. In (b) a detailed view is shown, the circle points out that the half-dislocation loop pins a $90^{\circ}$ a-domain. The plan-view TEM image displayed in (c) reveals the $90^{\circ}$ domains and the dark-spots are the terminations of threading dislocations on the PZT top surface, which can be better seen in (d). In (e) a contrast inverted cross-sectional electron diffraction pattern (beam direction [010]), correctly rotated with respect to Fig. 2a, is given. Three reflections are indexed, on the bottom right $45^{\circ}$-oriented streaks due to the habit planes of the $90^{\circ}$ ac-boundaries are seen.

Figure 3 (110)-Fourier filtered plan-view HRTEM of a single TD dipole, with a separation distance of about $15 \mathrm{~nm}$. 
Figure 4 HRTEM of a single threading dislocation half-loop, with a separation distance of about $20 \mathrm{~nm}$, seen from the [010] direction in (a), and a detailed view in (b). In (a) the white line is added as a guide to the position of the dislocation. The black boxes and arrows in (b) designate the vertical position of the unit cells on the left and right of the stacking fault.

Figure 5 Threading dislocation dipoles with a stacking fault (SF), indicated by the black arrow. a- diffraction contrast cross-section TEM image (seen from [110] direction), and b- cross-section HRTEM micrograph (seen from [110] direction). A HRTEM micrograph (seen from [1 $1 \overline{10}]$ direction), where the (001) PZT planes and the stacking fault are seen edge-on, is given in (c).

Figure 6 A possible schematic model of the stacking fault seen from [1 10$]$ direction: along the $\mathrm{SF}$ edge, oxygen ions are missing and metallic $\mathrm{Pb}$ atoms are paired. The top center schematic is seen from [001] direction.

Figure 7 Cross-section HRTEM micrograph revealing that a threading dislocation dipole may nucleate on an amorphous particle "P" at the PZT/SRO interface, that can be better seen in the inset (upper left corner). 

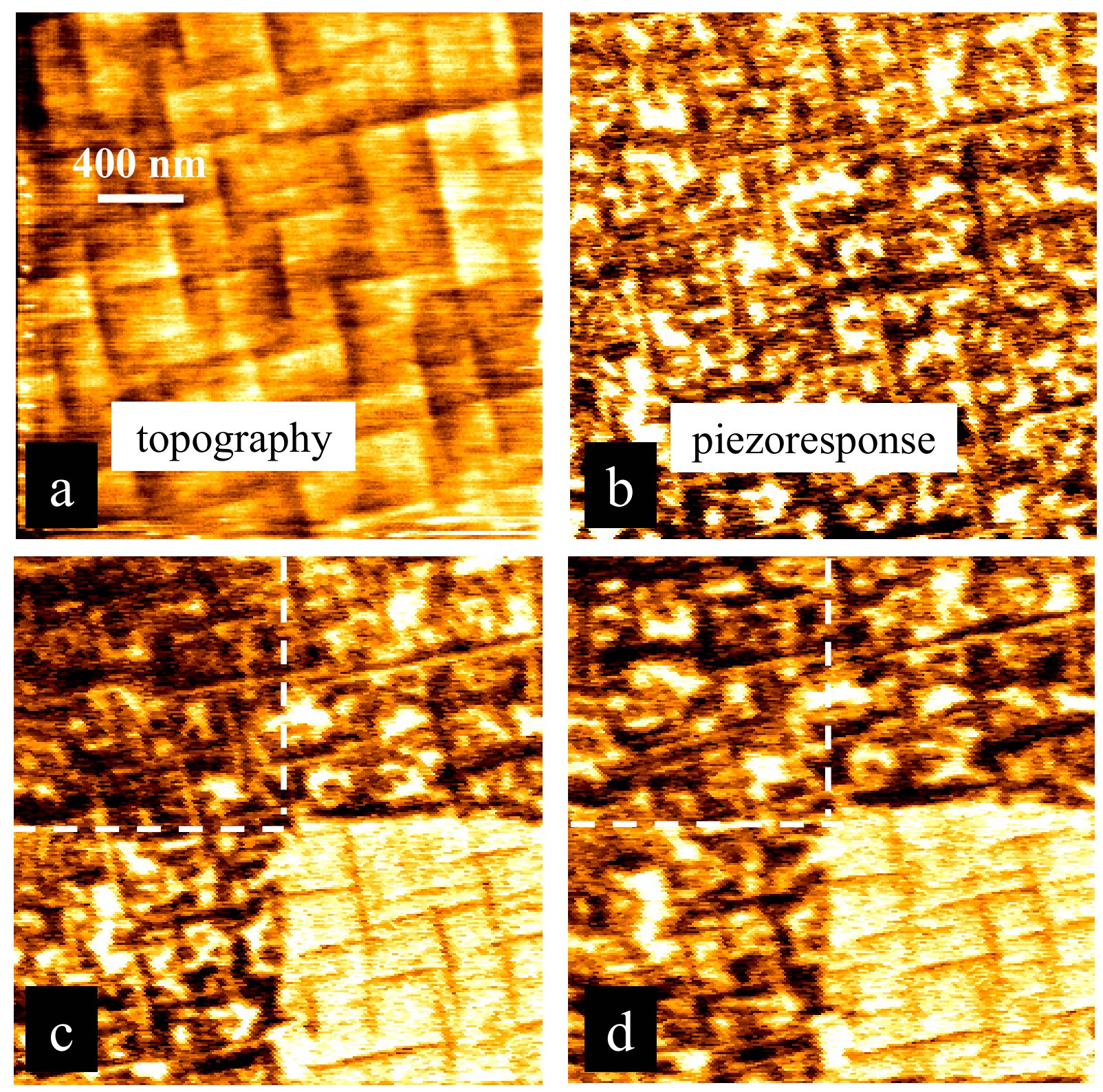

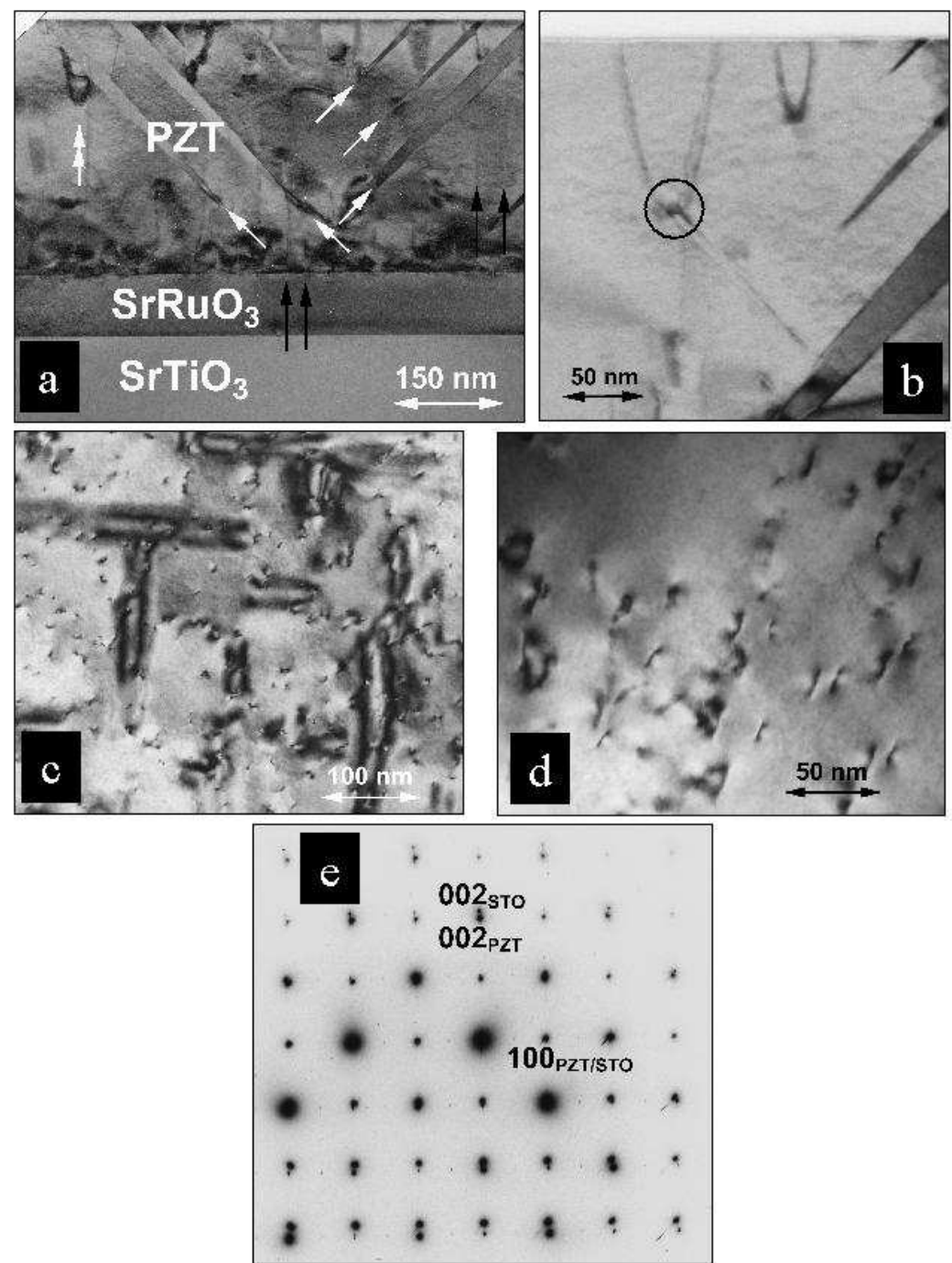

$190 \times 253 \mathrm{~mm}(96 \times 96$ DPI $)$ 


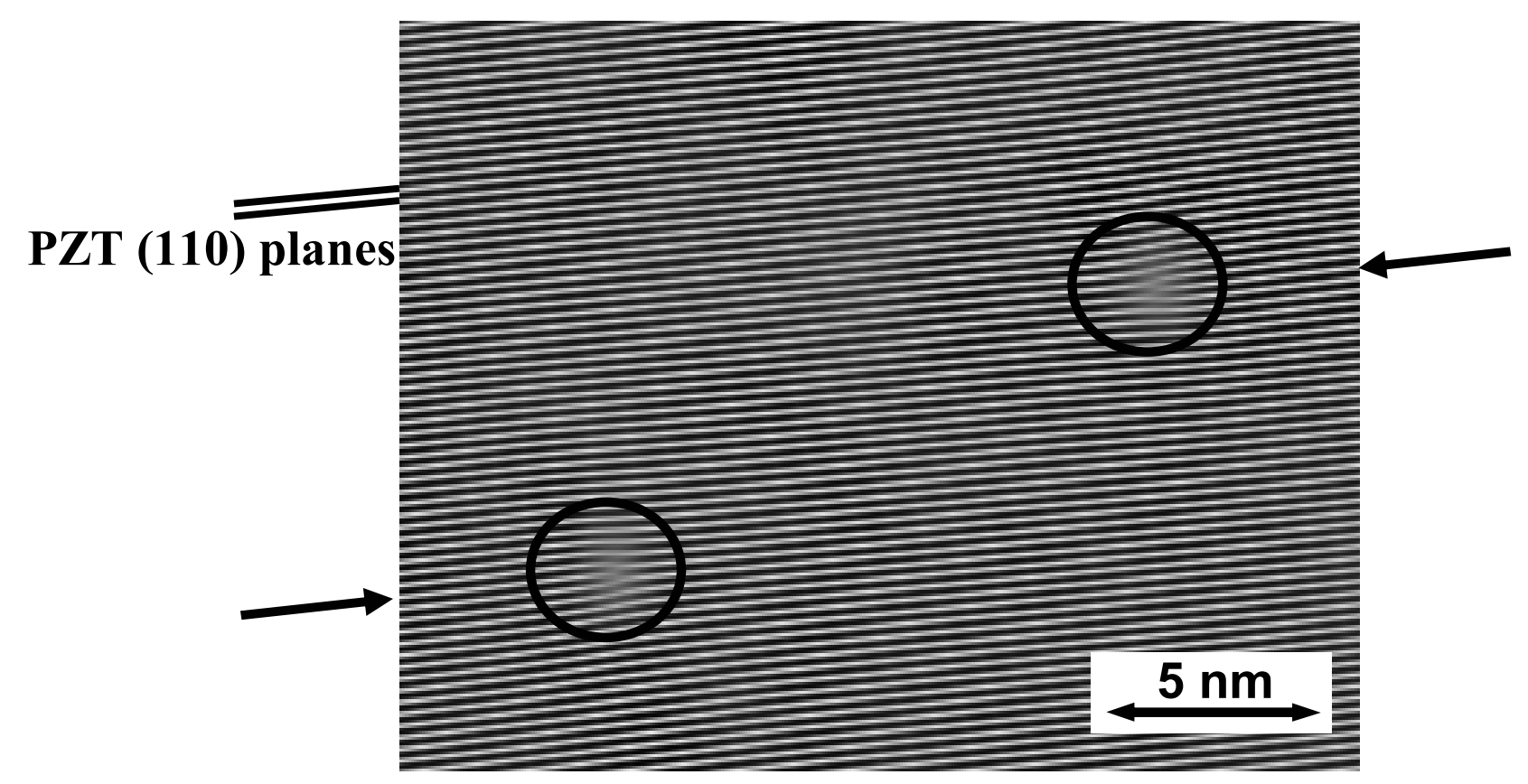



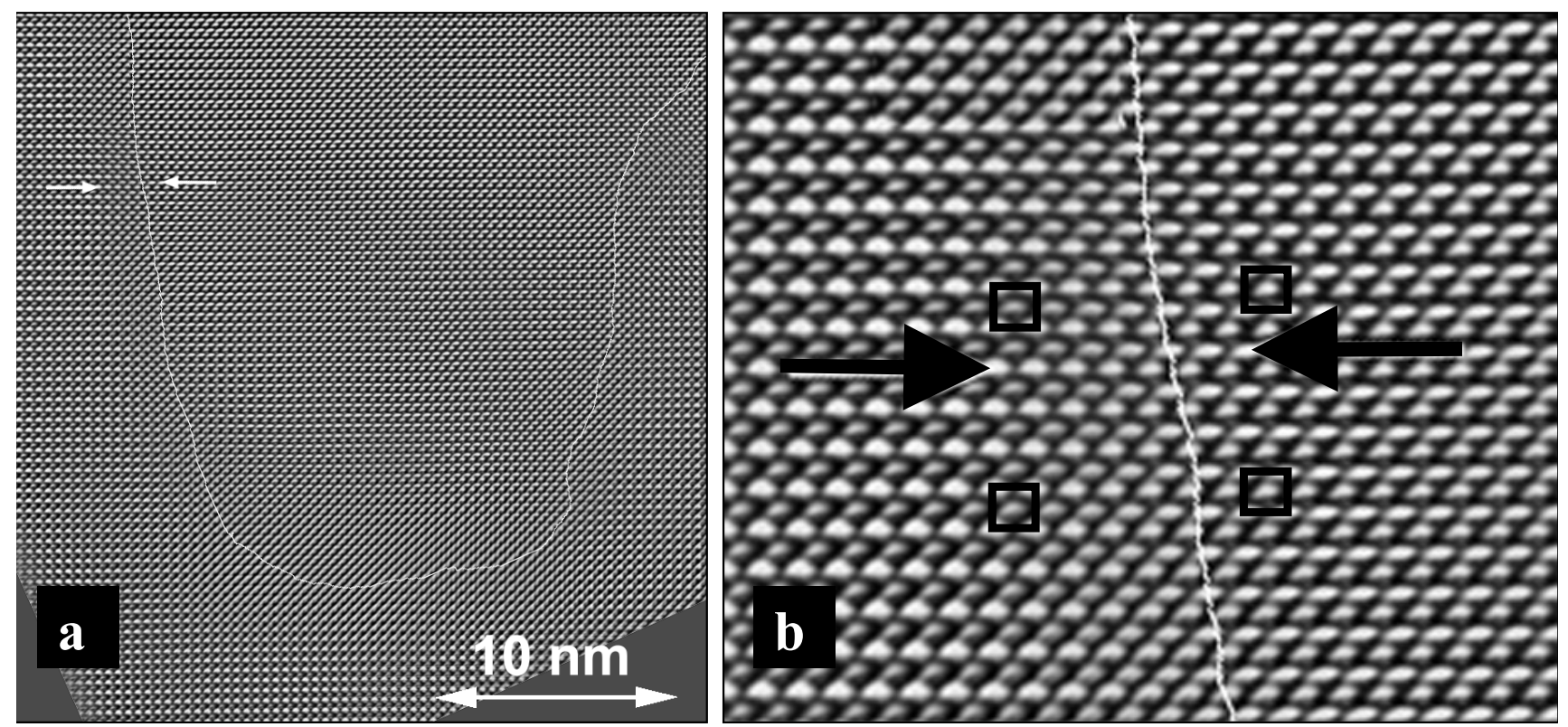

Seen from [010] 

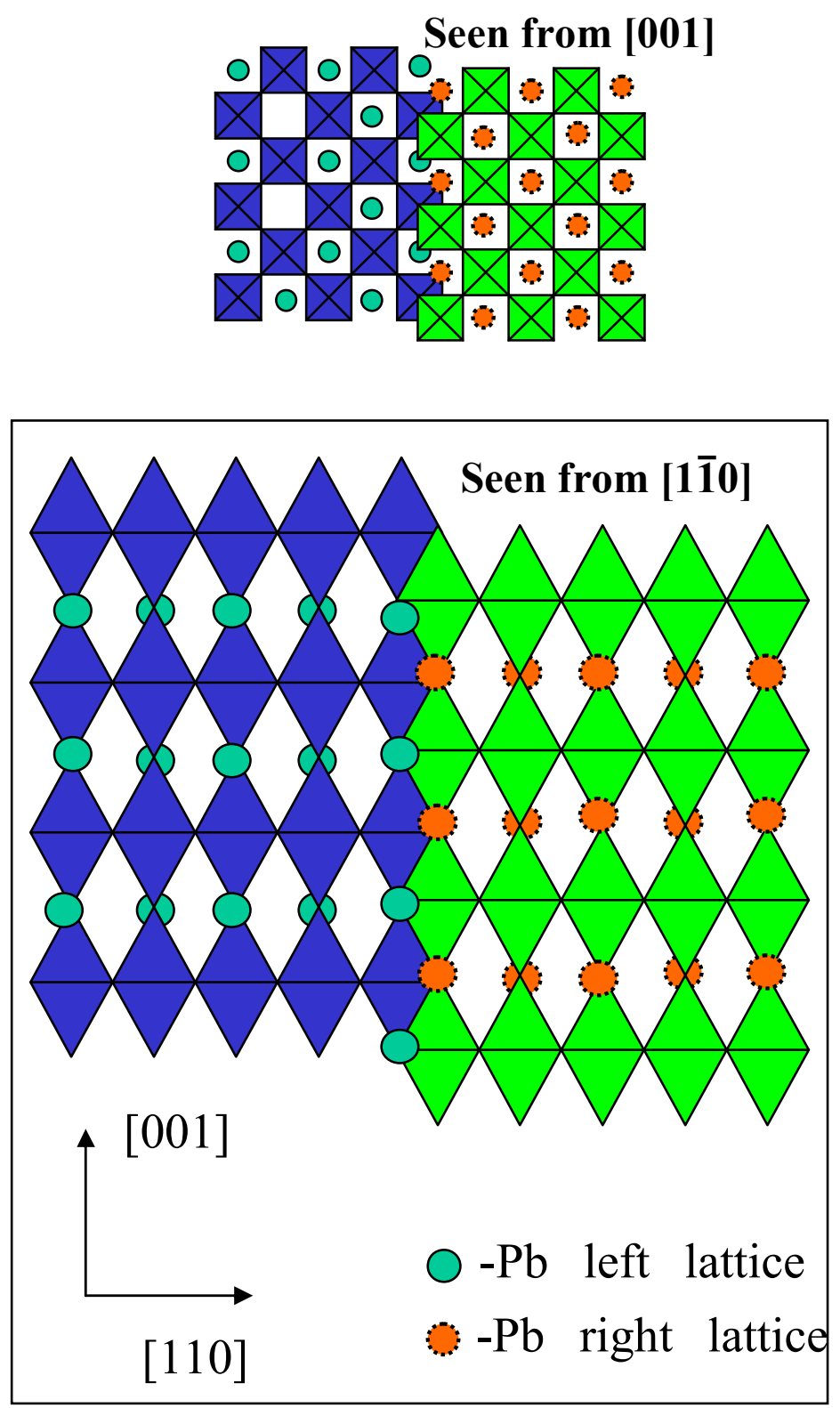


\section{Page2 21 ofriliosophical Magazine \& Philosophical Magazine Letters}

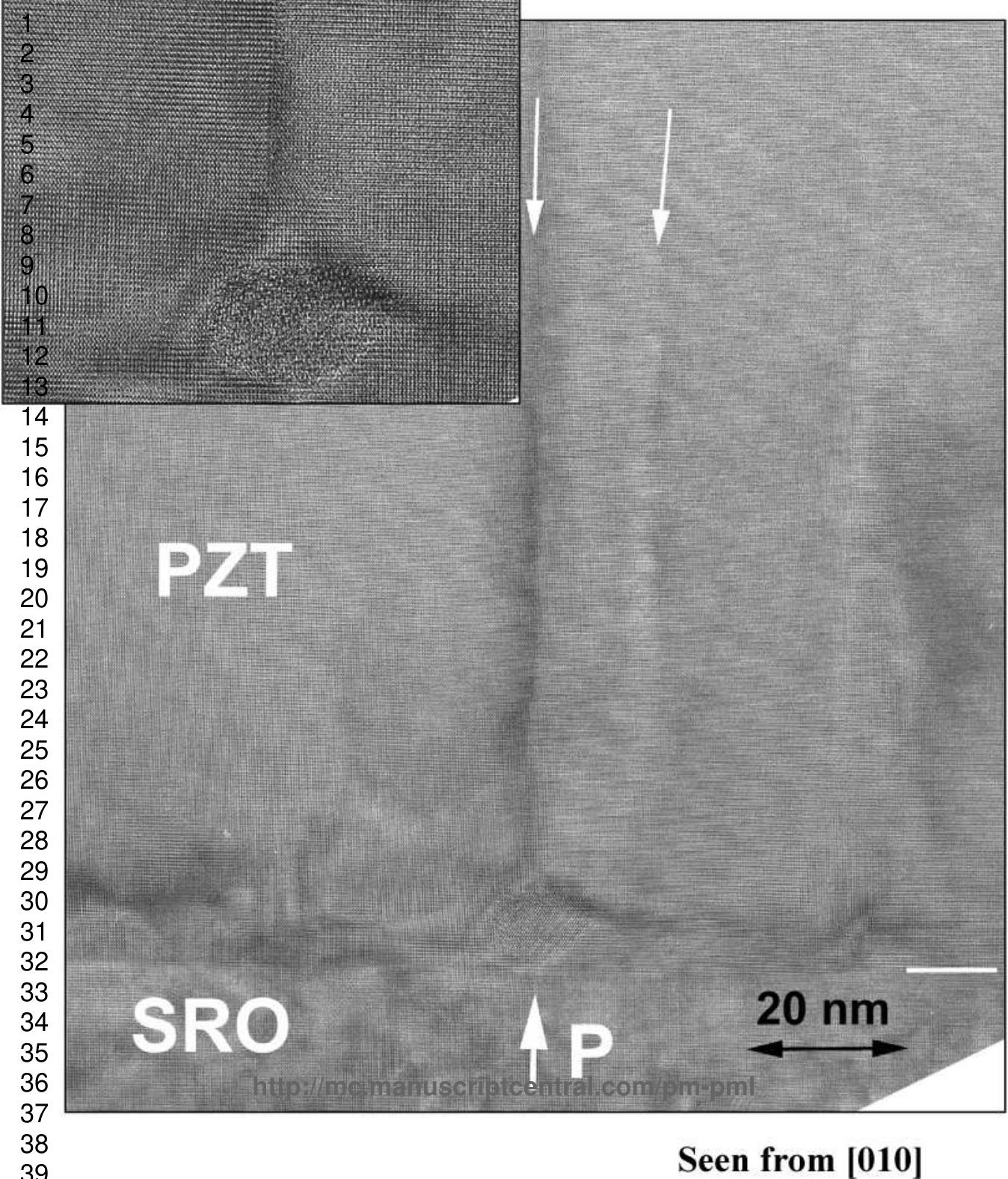

